\title{
Notes on Hyperinflations
}

\author{
Sumru G. Altug \\ Koç UNiversity and CEPR ${ }^{1}$
}

October 13, 2008

\footnotetext{
${ }^{1}$ These notes were written while I was an Assistant Professor at the Department of Economics at the University of Minnesota. They were initially circulated as Federal Reserve Bank of Minneapolis Working Paper 343, 1987. I developed the material for these notes as part of my teaching of Graduate Macroeconomics in the Economics Department.
} 


\section{Introduction}

In his introduction to the "The Monetary Dynamics of Hyperinflations," Phillip Cagan notes that hyperinflations have been studied extensively in the past because they offer a unique opportunity to examine monetary phenomena. During hyperinflations there are astronomical increases in prices.

Consider the following data on 20 'th century hyperinflations.

Average Monthly Inflation

\begin{tabular}{lcc} 
& & Rate \\
\hline Austria & $1921-1922$ & $47.1 \%$ \\
Germany & $1920-1923$ & $322 \%$ \\
Greece & $1943-1944$ & $365 \%$ \\
Hungary & $1922-1924$ & $46 \%$ \\
Hungary & $1945-1946$ & $19,800 \%$ \\
Poland & $1922-1923$ & $81.4 \%$ \\
Russia & $1921-1924$ & $57 \%$ \\
\hline
\end{tabular}

Another characteristic of hyperinflations is that real case balances, defined as $M / P$, tend to fall whereas in ordinary inflations, they tend to rise.

Phillip Cagan studied the hyperinflations listed above. He argued that, because the rate of change of prices fluctuates so extremely during hyperinflations, the variations in real cash balances depend mainly on variations in the expected rate of change of prices. In other words, he assumed that other possible determinants of the variation in real cash balances, such as the change in real income, could not account for the variation in real cash balances observed during hyperinflations.

\section{A Model}

Following Sargent (1979), the model that Cagan used can be represented by letting $m_{t}$ be the log of the money supply (currency and deposits), 
$p_{t}$ be the log of the price level,

$p_{t+1}^{e}$ be the log of the price level expected to prevail at time $t+1$, given information at time $t$,

and by assuming that the log of money demand for real balances by individuals can be expressed as

$$
m_{d}^{t}=\alpha\left(p_{t+1}^{e}-p_{t}\right), \quad \alpha<0 .
$$

Hence, the demand for real balances varies inversely with the expected inflation rate. Equating the supply of money with the demand for money implies the portfolio balance equation

$$
m_{t}-p_{t}=\alpha\left(p_{t+1}^{e}-p_{t}\right), \quad \alpha<0 .
$$

Cagan assumed that expected inflation could be written as

$$
p_{t+1}^{e}=\gamma\left(p_{t}-p_{t-1}\right)
$$

i.e., proportional to past inflation. This yields $m_{t}-p_{t}=\gamma\left(p_{t}-t-1\right)$, or $[(\alpha \gamma+1)-\alpha \gamma L] p_{t}=$ $m_{t}$, where $L$ is the lag operator, i.e., $L x_{t}=x_{t-1}$. Thus, we have

$$
\left[1-\frac{\alpha \gamma}{\alpha \gamma+1} L\right] p_{t}=\frac{1}{\alpha \gamma+1} m_{t}
$$

Again following Sargent (1979), the solution is

$$
p_{t}=\frac{1}{\alpha \gamma+1} \sum_{i=0}^{\infty}(\alpha \gamma)^{i} m_{t-i}+\left(\frac{\alpha \gamma}{\alpha \gamma+1}\right)^{t} c,
$$

where $c$ is a constant to be determined by some initial condition or the value of $p_{t}$ at a point in time. Equation (2.4) describes the behavior of the price level as a function of the current and past values of an exogenous money supply process. Notice that we will get a bounded price level when

$$
\left|\frac{\alpha \gamma}{\alpha \gamma+1}\right|<1
$$

and we are given a bounded sequence for the money supply process. Hence, if $m_{t}^{\prime}=m_{t}+\Delta$ for all $t$, then $p_{t}^{\prime}=p_{t}+\Delta$ for all $t$. Consequently, a once and for all increase in the stock 
of currency and deposits leads to a once and for all increase in prices. This is a longrun version of the quantity theory of money, which says that, under given conditions, real cash balances $M / P$ remain proportional to real income $X$, i.e., $M / P=k X$, where $k$ is a constant. Another way of expressing this fact is that $M V=P X$, where $V$ is the velocity of circulation of money. So, if $V$ does not change or the demand for real balances remains constant, then an increase in $M$ leads to a proportionate increase in $P$.

According to this definition, the quantity theory holds in the strict sense in Cagan's model iff $\alpha=0$, i.e.,

$$
m_{t}-p_{t}=\alpha\left(p_{t+1}^{e}-p_{t}\right) \Rightarrow \frac{M_{t}}{P_{t}}=1
$$

whenever $\alpha=0$, or with a constant term,

$$
m_{t}-p_{t}=\alpha\left(p_{t+1}^{e}-p_{t}\right) \Rightarrow \frac{M_{t}}{P_{t}}=\exp (\psi) \equiv k X
$$

for a given $X$ and $k$.

Cagan assumed that expectations of inflation were adaptive and the stock of money (i.e. currency and demand deposits) are exogenously determined with respect to the price level. This yields a solution for prices which depends on past values of the money stock. Others were arguing that one key aspect of hyperinflations is their self-sustaining character: the price level increases because people expect it to increase. One way to incorporate this idea is to change the assumption by which expectations are formed. Let us assume a very simple mechanism: perfect foresight, i.e.,

$$
p_{t+1}^{e}=p_{t} \quad \forall t .
$$

Then, $m_{t}-p_{t}=\alpha p_{t+1}-\alpha p_{t}$, or

$$
(1-\alpha) p_{t}=-\alpha p_{t+1}+m_{t},
$$

which implies that

$$
\begin{aligned}
p_{t} & =\frac{-\alpha}{1-\alpha} p_{t+1}+\frac{1}{1-\alpha} m_{t}, \\
& =\lambda p_{t+1}+\delta m_{t},
\end{aligned}
$$


with $\delta>0$ and $\lambda \in(0,1)$ since $\alpha<0$.

Hence, the price today depends on the price tomorrow and incorporates the self-sustaining character of hyperinflations. How do we solve for the price level today? A standard way is to proceed as in Sargent, p. 193-104. Another way is to proceed is to use the contraction mapping theorem. Suppose we are given a nonexplosive money supply sequence and we want to find a non-explosive price level sequence that satisfies the portfolio balance equation.

More precisely, given

$$
\left\{m_{t}\right\}_{t=0}^{\infty} \in\left(l_{2}[0, \infty), d_{2}\right) \text {, i.e. } \sum_{t=0}^{\infty} m_{t}^{2}<\infty,
$$

find a solution

$$
\left\{p_{t}^{*}\right\}_{t=0}^{\infty} \in\left(l_{2}[0, \infty), d_{2}\right)
$$

such that $\sum_{t=0}^{\infty}\left(p_{t}^{*}\right)^{2}<\infty$ and $p_{t}^{*}=\lambda p_{t+1}^{*}+\delta m_{t}$ for all $t$, where the metric $d_{2}(x, y)$ is defined as

$$
d_{2}(x, y)=\left\{\sum_{t=0}^{\infty}\left(x_{t}-y_{t}\right)^{2}\right\}^{1 / 2}
$$

for $\left\{x_{t}\right\}_{t=0}^{\infty},\left\{y_{t}\right\}_{t=0}^{\infty} \in l_{2}$.

Notice that the difference equation

$$
p_{t}=\lambda p_{t+1}+\delta m_{t}
$$

is a functional equation: For a given $m \equiv\left\{m_{t}\right\}_{t=0}^{\infty} \in\left(l_{2}, d_{2}\right)$, it shows how to map $p^{0} \equiv$ $\left\{p_{t}\right\}_{t=0}^{\infty} \in\left(l_{2}, d_{2}\right)$ into another point $p^{1} \equiv\left\{p_{t}^{1}\right\}_{t=0}^{\infty} \in\left(d_{2}, l_{2}\right)$. Hence, we can define an operator $T(p)$

$$
\left[T\left(p^{0}\right)\right]_{t}=\lambda p_{t+1}^{0}+\delta m_{t},
$$

such that

$$
p_{t}^{1}=\left[T\left(p^{0}\right)\right]_{t}=\lambda p_{t+1}^{0}+\delta m_{t} \forall t .
$$

We are looking for a fixed point of the operator $T$, i.e. a point $p^{*}$ such that

$$
T\left(p^{*}\right)=p^{*},
$$


or

$$
p_{t}^{*}=\lambda p_{t+1}^{*}+\delta m_{t}, \quad t \geq 0 .
$$

How can we show that such a fixed point exists? By the contraction mapping theorem. If $T$ is a contraction in a complete metric space, then $T$ has a unique fixed point. Is $\left(l_{2}, d_{2}\right)$ complete? Yes! Is $T$ a contraction? Pick any $\bar{p}, \tilde{p} \in l_{2}$. Then

$$
d(\bar{p}, \tilde{p})=\left\{\sum_{t=0}^{\infty}\left(\bar{p}_{t}-\tilde{p}_{t}\right)^{2}\right\}^{1 / 2} .
$$

But

$$
\begin{aligned}
d(\bar{p}, \tilde{p}) & =\left\{\sum_{t=0}^{\infty}\left(\lambda \bar{p}_{t}+\delta m_{t}-\lambda \tilde{p}_{t}-\delta m_{t}\right)^{2}\right\}^{1 / 2} \\
& =\left\{\sum_{t=0}^{\infty} \lambda^{2}\left(\bar{p}_{t}-\tilde{p}_{t}\right)^{2}\right\}^{1 / 2} \\
& =\left\{\lambda^{2}\left(\bar{p}_{t}-\tilde{p}_{t}\right)^{2}-\left(\bar{p}_{0}-\tilde{p}_{0}\right)^{2}\right\}^{1 / 2} \\
& =\lambda\left\{d(\bar{p}, \tilde{p})-(\bar{p}-\tilde{p})^{2}\right\}^{1 / 2} \\
& \leq \lambda d(\bar{p}, \tilde{p}) \\
& <d(\bar{p}, \tilde{p}) .
\end{aligned}
$$

By showing that the mapping $T$ defined by the functional equation

$$
\left[T\left(p^{0}\right)\right]_{t}=\lambda p_{t+1}^{0}+\delta m_{t}
$$

is a contraction in a complete metric space, we have shown the existence of a fixed point or solution to the difference equation

$$
p_{t}=\lambda p_{t+1}+\delta m_{t} .
$$

But how we characterize this fixed point? The contraction mapping theorem says that we can iterate on a given point $p^{0}$ to find the fixed point $p^{*}$. Let

$$
p^{0}=\left\{p_{t}^{0}\right\}_{t=0}^{\infty}=\{0\}_{t=0}^{\infty} .
$$


Now

$$
\begin{aligned}
{\left[T\left(p^{0}\right)\right]_{t} } & =\lambda p_{t+1}^{0}+\delta m_{t} \\
& =\delta m_{t} \forall t, \text { i.e., } p^{1}=\left\{p_{t}^{1}\right\}_{t=0}^{\infty}=\left\{\delta m_{t}\right\}_{t=0}^{\infty} \\
{\left[T\left(p^{1}\right)\right]_{t} } & =\lambda\left[\delta m_{t+1}\right]+\delta m_{t}=\delta\left[\lambda m_{t+1}+m_{t}\right] \forall t \\
{\left[T\left(p^{2}\right)\right]_{t} } & =\lambda\left[\lambda \delta m_{t+2}+\delta m_{t+1}\right]+\delta m_{t} \forall t \\
& =\delta\left[\lambda^{2} m_{t+2}+\lambda m_{t+1}+m_{t}\right] \\
\vdots & =\vdots \\
{\left[T\left(p^{n}\right)\right]_{t} } & =\delta \sum_{i=0}^{n} \lambda^{i} m_{t+i} \forall t .
\end{aligned}
$$

To show that

$$
\lim _{n \rightarrow \infty} p^{n} \rightarrow p^{*},
$$

where $p_{t}^{n}=\delta \sum_{i=0}^{n} \lambda^{i} m_{t+i}$ and $p_{t}^{*}=\sum_{i=0}^{\infty} \lambda^{i} m_{t+i}$, consider

$$
\begin{aligned}
d\left(p^{n}, p^{*}\right) & =\sum_{t=0}^{\infty}\left(p_{t}^{n}-p_{t}^{*}\right)^{2} \\
& =\sum_{t=0}^{\infty}\left(\delta \sum_{i=n}^{\infty} \lambda^{i} m_{t+i}\right)^{2} \\
& =\lambda^{2 n} \sum_{t=0}^{\infty}\left(\delta \sum_{i=0}^{\infty} \lambda^{i} m_{t+i+n}\right)^{2} \\
& =\lambda^{2 n} \sum_{t=0}^{\infty}\left(p_{t+n}^{*}\right)^{2} \\
& \leq \lambda^{2 n} M,
\end{aligned}
$$


since $\sum_{t=0}^{\infty}\left(p_{t+n}^{*}\right)^{2}<M$ for any $n$, where $M$ is some positive real number. Since $\delta>0$, $d\left(p^{n}, p^{*}\right)<\epsilon$ whenever $n>N_{\epsilon} \cdot{ }^{1}$ Thus, we have that

$$
\lim _{n \rightarrow \infty} p^{n} \rightarrow p^{*}
$$

But recall that there exist other solutions to the difference equation that do not lie in $\left(l_{2}, d_{2}\right)$. In particular, from Sargent (1979), we know that

$$
\tilde{p}_{t}=\delta \sum_{i=0}^{\infty} \lambda^{i} m_{t+i}+c\left(\frac{1}{\lambda}\right)^{t}
$$

also satisfies the portfolio balance equation. Since $1 / \lambda>1$, it is clear that $\sum_{t=0}^{\infty} \tilde{p}_{t}^{2}$ is not finite; hence, $\tilde{p}=\left\{\tilde{p}_{t}\right\}_{t=0}^{\infty}$ is not an element of $l_{2}$.

\section{Cagan's Empirical Results}

Cagan estimated his model by adding an error term and using OLS, i.e.,

$$
m_{t}-p_{t}=\alpha \pi_{t}^{e}+\psi+\epsilon_{t}, \quad \alpha<0,
$$

and

$$
\pi_{t}^{e}=(1-\eta) \sum_{i=0}^{\infty} \eta^{i} \log \left(\frac{P_{t-i}}{P_{t-i-1}}\right), 0 \leq \eta \leq 1 .
$$

The estimates that he found were as follows:

\footnotetext{
${ }^{1}$ To solve for $N_{\epsilon}$, use $\epsilon=\lambda^{2 n} M$ and take $\operatorname{logs}$. This implies $\log \epsilon=2 n \log \lambda+\log M$. Thus, $N_{\epsilon}=$ $(\log \epsilon-\log M) / 2 \log \lambda$.
} 


\begin{tabular}{|c|c|c|c|c|}
\hline Country & $\begin{array}{l}\text { Time } \\
\text { Period }\end{array}$ & $\begin{array}{c}-\alpha \\
\text { (in months) }\end{array}$ & $\begin{array}{c}\text { Confidence } \\
\text { Interval }\end{array}$ & $R^{2}$ \\
\hline Austria & $\begin{array}{l}\text { Jan. 1921- } \\
\text { Aug. } 1922\end{array}$ & 8.55 & $4.43-0.31$ & 0.989 \\
\hline Germany & $\begin{array}{l}\text { Sept. } 1920 \text { - } \\
\text { July } 1923\end{array}$ & 5.46 & $5.50-6.31$ & 0.992 \\
\hline Greece & $\begin{array}{l}\text { Jan. } 1943 \text { - } \\
\text { Aug. } 1944\end{array}$ & 4.09 & $2.83-32.5$ & 0.98 \\
\hline Hungary & $\begin{array}{l}\text { July } 1922- \\
\text { Feb. } 1924\end{array}$ & 8.70 & $6.36-42.2$ & .926 \\
\hline Hungary & $\begin{array}{l}\text { July } 1945 \text { - } \\
\text { Feb. } 1946\end{array}$ & 3.83 & $2.55-4.73$ & .998 \\
\hline Poland & $\begin{array}{l}\text { Apr. } 1922- \\
\text { Nov. } 1923\end{array}$ & 2.3 & $1.74-3.94$ & .972 \\
\hline Russia & $\begin{array}{l}\text { Dec. } 1921 \text { - } \\
\text { Jan. } 1924\end{array}$ & 3.06 & 2.663 .76 & .971 \\
\hline
\end{tabular}

Cagan found that the log of real money balances depended negatively on the expected inflation rate, where the parameter determining the evolution of inflation expectations $\eta$ was also estimated.

One problem that Cagan had, however, was that observations near the end of the hyperinflations did not fit the regression lines which he estimated. In particular, for a given value of the expected rate of price inflation, the quantity of real balances held at the end of the hyperinflations was higher than predicted by the regression equations.

The paper raised many issues which were studied subsequently. 


\section{Subsequent Work}

Sargent and Wallace (1973) re-estimated Cagan's model by assuming that expectations are rational, i.e., they assumed that

$$
\pi_{t}^{e}=E\left[p_{t+1}-p_{t} \mid I_{t}\right]
$$

where $p_{t}$ is the log of the price level at $t$ and $I_{t}$ denotes the information which agents in the economy have at date $t$ and which they use to forecast the value of next period's price.

This assumption leads to an expectational difference equation or a stochastic difference equation of the form:

$$
m_{t}-p_{t}=\alpha\left[E_{t}\left(p_{t+1} \mid I_{t}\right)-p_{t}\right]
$$

We will deal with ways of solving this type of difference equation more rigorously later

on. For now, will replace the rational expectations assumption with the perfect foresight assumption. Then we know that the fixed point sequence for this difference equation is given by

$$
p_{t}=\delta \sum_{i=0}^{\infty} \lambda^{i} m_{t+i}
$$

Suppose that we take a more realistic view of the process by which the money supply process is determined. In other words, suppose we assume that at a given point in time, the government has not determined the whole future path of money supplies, $\left\{m_{t}\right\}_{t=0}^{\infty}$. But if this is the case then we cannot determine the value of the perfect foresight price today because this depends on the whole future history of money supplies. However, we could assume that the government knows the rule by which the current stock of money is determined as a function of its past. One mechanism is to assume that

$$
m_{t}=a_{1} m_{t-1}+a_{2} m_{t-2}+\ldots+a_{n} m_{t-n} .
$$

Now our system is fully determined as

$$
\begin{aligned}
p_{t} & =\delta \sum_{i=0}^{\infty} \lambda^{i} m_{t+i} \\
m_{t} & =a_{1} m_{t-1}+a_{2} m_{t-2}+\ldots+a_{n} m_{t-n} .
\end{aligned}
$$


Typically we can take the money supply process to be an infinite distributed lag, i.e.,

$$
m_{t}=a_{1} m_{t-1}+a_{2} m_{t-2}+\ldots=\sum_{i=0}^{\infty} a_{i} m_{t-i},
$$

where the sequence of coefficients $\left\{a_{j}\right\}_{j=0}^{\infty}$ is in $l_{2}[0, \infty)$ and $a_{0}=-1$. We assume that $\left\{m_{t}\right\}_{t=-\infty}^{\infty} \in l_{2}(-\infty, \infty)$, i.e., $\sum_{i=-\infty}^{\infty} m_{t}^{2}<\infty$.

We know that there exists a solution to the difference equation

$$
p_{t}=\lambda p_{t+1}+\delta m_{t}, \quad \lambda \in(0,1), \quad \delta>0,
$$

which is given by

$$
p_{t}=\delta \sum_{i=0}^{\infty} \lambda^{i} m_{t-i} .
$$

Now we seek a solution of the form

$$
p_{t}=\sum_{j=0}^{\infty} b_{j} m_{t-j},
$$

where $\left\{b_{j}\right\}_{j=0}^{\infty} \in l_{2}[0, \infty)$. We claim that there is a unique solution of this form. Using the right-hand side of the difference equation for price, we will define the operator which maps sequences $\left\{b_{j}^{n}\right\}_{j=0}^{\infty}$ into sequences $\left\{b_{j}^{n+1}\right\}_{j=0}^{\infty}$. Substitute the expression in (4.9) into the expression for price $p_{t}=\lambda p_{t+1}+\delta m_{t}$ to obtain the identity

$$
\sum_{j=0}^{\infty} b_{j}^{n+1} m_{t-j}=\lambda\left(\sum_{j=0}^{\infty} b_{j}^{n} m_{t-j+1}\right)+\delta m_{t},
$$

or

$$
b_{0}^{n+1} m_{t}+b_{1}^{n+1} m_{t-1}+b_{2}^{n} m_{t-2}+\ldots=\lambda b_{0}^{n} m_{t+1}+\lambda b_{1}^{n} m_{t}+\lambda b_{2}^{n} m_{t-1}+\ldots+\delta m_{t} .
$$

Now substitute for $m_{t+1}=\sum_{i=1}^{\infty} m_{t+1+i}$ to obtain

$$
\begin{aligned}
& b_{0}^{n+1} m_{t}+b_{1}^{n+1} m_{t-1}+b_{2}^{n+1} m_{t-2}+\ldots= \\
& \quad \lambda b_{0}^{n}\left(a_{1} m_{t}+a_{2} m_{t-1}+a_{3} m_{t-2}+\ldots\right)+\lambda b_{1}^{n} m_{t}+\lambda b_{2}^{n} m_{t-1}+\ldots+\delta m_{t} .
\end{aligned}
$$

Equating the coefficients on $m_{t-i}$ for $i=0,1, \ldots$ yields

$$
\begin{aligned}
& b_{0}^{n+1}=\lambda b_{0}^{n}+\lambda b_{1}^{n}+\delta \\
& b_{j}^{n+1}=\lambda b_{0}^{n} a_{j+1}+\lambda b_{j+1}^{n}, \quad j \geq 1 .
\end{aligned}
$$


For any $b$ sequence, this yields the operator

$$
[T(b)]_{j}= \begin{cases}\lambda b_{0} a_{1}+\lambda b_{1}+\delta, & j=0 \\ \lambda b_{0} a_{j+1}+\lambda b_{j+1}, & j \geq 1 .\end{cases}
$$

We seek a fixed point for $(b)$. Thus, set $b=T(b)$ to obtain

$$
\begin{aligned}
& b_{0}=\lambda b_{0} a_{1}+\lambda b_{1}+\delta \\
& b_{j}=\lambda b_{j+1}+\lambda b_{0} a_{j+1}, \quad j \geq 1 .
\end{aligned}
$$

Now the second equation has a unique solution given by

$$
b_{j}=\lambda b_{0} \sum_{k=0}^{\infty} \lambda^{k} a_{k+j+1}, \quad j \geq 1 .
$$

If we can determine $b_{0}$, then the remaining terms are defined from (4.14). But to determine $b_{0}$, we need to solve

$$
\begin{aligned}
b_{0}\left(1-\lambda a_{1}\right) & =\lambda b_{1}+\delta \\
b_{1} & =b_{0} \sum_{k=0}^{\infty} \lambda^{k+1} a_{k+2} .
\end{aligned}
$$

Define

$$
\begin{aligned}
& a(L)=1-a_{1} L-a_{2} L^{2}-\ldots \\
& b(L)=b_{0}+b_{1} L+b_{2} L^{2}+\ldots
\end{aligned}
$$

Notice that

$$
\begin{aligned}
\lambda a_{2}+\lambda^{2} a_{3}+\lambda^{3} a_{4}+\ldots & =\lambda^{-1}-a_{1}-\lambda^{-1}\left(1-a_{1} \lambda-a_{2} \lambda-\ldots\right) \\
& =\lambda^{-1}-a_{1}-\lambda^{-1} a(\lambda) .
\end{aligned}
$$

Substituting into the expression for $b_{1}$ yields

$$
b_{1}=b_{0}\left(\lambda^{-1}-a_{1}-\lambda^{-1} a(\lambda)\right) .
$$


. But

$$
b_{1}=\left(b_{0}\left(1-a_{1} \lambda\right)-\delta\right) / \lambda .
$$

Equating the two expressions yields

$$
b_{0}\left(1-\lambda a_{1}\right)-\delta=b_{0}\left(1-a_{1} \lambda-a(\lambda)\right),
$$

which implies that

$$
b_{0}=\delta / a(\lambda)
$$

Then from

$$
b_{j}=b_{0} \sum_{k=0}^{\infty} \lambda^{k+1} a_{k+j+1},
$$

we get

$$
\begin{aligned}
b_{1} & =\delta a(\lambda)^{-1}\left(\lambda a_{2}+\lambda^{2} a_{3}+\ldots\right) \\
b_{2} & =\delta a(\lambda)^{-1}\left(\lambda a_{3}+\lambda^{2} a_{4}+\ldots\right) \\
\vdots & =\vdots
\end{aligned}
$$

or

$$
\begin{aligned}
b(L) & =b_{0}+b_{1} L+b_{2} L^{2}+\ldots \\
& =\delta a(\lambda)^{-1}\left[1+\left(\sum_{k=0}^{\infty} \lambda^{k+1} a_{k+1}\right) L+\left(\sum_{k=0}^{\infty} \lambda^{k+1} a_{k+2}\right) L^{2}+\ldots\right]
\end{aligned}
$$

This expression shows the Rational Expectations cross-equation restrictions between an endogenous process and the exogenous process driving it.

It is worthwhile comparing this expression with the solution to Cagan's model, i.e.,

$$
p_{t}=\frac{1}{\alpha \gamma} \sum_{i=0}^{\infty}\left(\frac{\alpha \gamma}{\alpha \gamma+1}\right)^{i} m_{t-i}+\left(\frac{\alpha \gamma}{\alpha \gamma+1}\right)^{t} c,
$$

$\left\{m_{t-i}\right\}_{i=0}^{\infty}$ given. 
In this case, the expression for price depends on current and past values of the money supply and not on the future. Hence, to determine price in period $t$, all we have to know is the history of money supplies at $t$. With Rational Expectations or perfect foresight, however, we have to worry about the entire future path of the money supply, or equivalently, the money supply rule generating money supplies at every possible date. Consequently, if there is an unanticipated shift in the money supply rule at date $t$, then the expression determining the equilibrium price also shifts at date $t$ and afterwards. This is the heart of the Lucas Critique about government policy evaluation under Rational Expectations. Shifts in policy rules cause shifts in equilibrium relationships because the public takes into account the future when making its current decisions.

The above discussion assumes that the money stock is exogenously determined and evolves as a function of its finite past. In their 1973 article, "Rational Expectations and the Dynamics of Hyperinflations," Sargent and Wallace argue that money creation during hyperinflations may not be exogenous because the government is usually resorting to money creation to finance its government expenditures. They argue that "in order to keep its real expenditures at the level it desires, the government is likely to respond to a decline in the purchasing power of money by increasing the rate at which it is adding to the stock of money. Such behavior makes the rate of increase in the money supply depend partly on the price level, thus setting up a feedback from the public's expected rate of inflation, which determines the price level, to the rate of money creation." (See page 411, S \& W).

To model this, notice that very simple form of the government budget constraint is

$$
M_{t+1}-M_{t}=P_{t}\left(G_{t}-T_{t}\right), \quad t \geq 0 .
$$

Suppose that the government wishes to keep $G_{t}-T_{t}=\tilde{\mu}$ for all $t \geq 0$. Then if $P_{t}$ increases, then the rate of money creation also increases. Dividing through by $M_{t}$ and getting $g_{t} \equiv$ $M_{t+1} / M_{t}-1$ denote the rate of money growth, the government budget constraint becomes

$$
\frac{M_{t+1}}{M_{t}}-=\frac{P_{t}}{M_{t}} \tilde{\mu}
$$

Substituting for $g_{t}$ and taking logs yields

$$
\log g_{t}=\log P_{t}-\log M_{t} \log \tilde{\mu},
$$


or

$$
m_{t}-p_{t}=\log \tilde{\mu}-\log g_{t} .
$$

But Cagan's portfolio balance equation says that

$$
m_{t}-p_{t}=\alpha\left(p_{t+1}^{e}-p_{t}\right)
$$

Using the previous equation to eliminate $m_{t}-p_{t}$ implies

$$
\log \tilde{\mu}-\log g_{t}=\alpha\left(p_{t+1}^{e}-p_{t}\right)
$$

With perfect foresight, this becomes

$$
\log \tilde{\mu}-\log g_{t}=\alpha\left(p_{t+1}-p_{t}\right) .
$$

This equilibrium relation says that the public's expected rate of inflation helps determine the rate of money creation.

Sargent and Wallace argue that if this is the case, then Cagan's adaptive expectations mechanism is actually rational. Recall that Cagan assumes

$$
p_{t+1}^{e}-p_{t}=\alpha\left(p_{t}-p_{t-1}\right)
$$

Under perfect foresight, we require

$$
p_{t+1}^{e}-p_{t}=p_{t+1}-p_{t}=\frac{1}{1-\alpha} \sum_{i=0}^{\infty}\left(\frac{-\alpha}{1-\alpha}\right)^{i}\left(m_{t+i+1}-m_{t+i}\right) .
$$

If Cagan's scheme is rational, we require

$$
\gamma\left(p_{t}-p_{t-1}\right)=\frac{1}{1-\alpha} \sum_{i=0}^{\infty}\left(\frac{-\alpha}{1-\alpha}\right)^{i}\left(m_{t+i+1}-m_{t+i}\right) .
$$

A sufficient condition for (4.33) to hold is that

$$
m_{t+i+1}-m_{t+i}=m_{t+1}-m_{t} \forall i \geq 0 .
$$

Substituting this expression into (4.33) yields

$$
\gamma\left(p_{t}-p_{t-1}\right)=\frac{1}{1-\alpha} \sum_{i=0}^{\infty}\left(\frac{-\alpha}{1-\alpha}\right)^{i}\left(m_{t+1}-m_{t}\right),
$$


or

$$
\gamma\left(p_{t}-p_{t-1}\right)=\left(m_{t+1}-m_{t}\right)
$$

since

$$
\frac{1}{1-\alpha} \sum_{i=0}^{\infty}\left(\frac{-\alpha}{1-\alpha}\right)^{i}=1 .
$$

But recall that the condition in (4.35) is approximately equal to the expression for the rate of money creation that we obtained under the policy of financing a constant level of real expenditures by money creation, i.e.,

$$
\begin{aligned}
p_{t+1}-p_{t} & =-\frac{1}{\alpha}\left(\log g_{t}-\log \tilde{\mu}\right) \\
& =-\frac{1}{\alpha}\left(m_{t+1}-m_{t}\right)+\frac{1}{\alpha} \log \tilde{\mu} .
\end{aligned}
$$

Hence, if the rate of money growth equals the expected rate of inflation, Cagan's adaptive scheme is rational. But we showed that such a money stock process would arise if the government was trying to finance a given real amount of expenditures by money creation. Alternatively, this money supply rule would arise if the government were trying to supply the amount of money demanded by the public or peg the growth of real balances. As Sargent (1977) notes, during the German hyperinflation, German monetary officials acknowledged that they were operating under a "real bills" regime, in effect arguing that their actions were not causing inflation but merely responding to it.

\section{Price Bubbles}

Another issue that was raised by the Cagan article is the possibility that prices displayed explosive behavior during the post World War I hyperinflationary periods. Flood and Garber (1982) study this possibility. They work with the version of the Cagan model which assumes

$$
m_{t}-p_{t}=\alpha\left(p_{t+1}^{e}-p_{t}\right)+A_{0}
$$


and note that one solution to this difference equation is the sequence whose elements are defined by

$$
p_{t}=\frac{1}{1-\alpha} \sum_{i=0}^{\infty}\left(\frac{-\alpha}{1-\alpha}\right)^{i} m_{t+i}+c\left(\frac{\alpha-1}{\alpha}\right)^{t},
$$

where $(\alpha-1) / \alpha>1$ since $\alpha<0$.

They call the first term the "market fundamental" and the second term a "bubble." Hence, even if $m_{t}=\bar{m}$ for all $t, p_{t}$ will grow at an ever accelerating rate if $c \neq 0$. Flood and Garber (1982) do not show whether such explosive behavior is consistent with equilibrium in a fully-formulated model. Furthermore, they consider a very simple form of the so-called "bubble." It is easy to show the existence of other types of bubbles.

One solution to the difference equation is

$$
p_{t}=\frac{1}{1-\alpha} \sum_{i=0}^{\infty} \lambda^{i} m_{t+i}+c_{t},
$$

where $c_{t+1}=\lambda^{-1} c_{t}$.

To verify that (5.3) is a solution to the portfolio balance equation, notice that

$$
\begin{aligned}
\frac{1}{1-\alpha} \sum_{i=0}^{\infty} \lambda^{i} m_{t+i}+c_{t} & =\lambda\left\{\frac{1}{1-\alpha} \sum_{i=0}^{\infty} \lambda^{i} m_{t+i+1}+c_{t+1}\right\}+\frac{1}{1-\alpha} m_{t} \\
& =\frac{1}{1-\alpha}\left\{m_{t}+\sum_{i=1}^{\infty} \lambda^{i} m_{t+i}+\lambda \lambda^{-1} c_{t}\right\} \\
& =\frac{1}{1-\alpha} \sum_{i=0}^{\infty} \lambda^{i} m_{t+i}+c_{t} .
\end{aligned}
$$

Thus Flood and Garber consider only the bubble $c_{t}=c_{0} \lambda^{-t}$. But this "bubble" never pops; it continues to grow forever. Another possibility is to consider the bubble suggested by Blanchard and Watson (1983):

$$
c_{t}=\left\{\begin{array}{l}
(\pi \lambda)^{-1} c_{t+1} \text { with probability } \pi \\
0 \text { with probability } 1-\pi
\end{array}\right.
$$

To see that this will also yield a solution to the difference equation implied by Cagan's portfolio balance equation, notice that

$$
\frac{1}{1-\alpha} \sum_{i=0}^{\infty} \lambda^{i} m_{t+i}+c_{t}=\lambda\left\{\frac{1}{1-\alpha} \sum_{i=0}^{\infty} \lambda^{i} m_{t+i+1}+\pi(\pi \lambda)^{-1} c_{t}\right\}+\frac{1}{1-\alpha} m_{t}
$$




$$
\begin{aligned}
& =\frac{1}{1-\alpha}\left\{\sum_{i=0}^{\infty} \lambda^{i} m_{t+i}+\pi \lambda(\pi \lambda)^{-1} c_{t}\right\} \\
& =\frac{1}{1-\alpha} \sum_{i=0}^{\infty} \lambda^{i} m_{t+i}+c_{t} .
\end{aligned}
$$

Here $\pi$ is independent of how high price is. It may be that $\pi$ depends on how long the bubble has lasted or far price deviated from its market fundamental, i.e., from $\frac{1}{1-\alpha} \sum_{i=0}^{\infty} \lambda^{i} m_{t+i}$.

Flood and Garber (1980) test for the existence of bubbles of three possible durations during the German hyperinflation:

July 1920 to June 1923

June 1922 to June 1923

January 1923 to June 1923

They use data only up June 1923, whereas the hyperinflation in Germany ended in November 1923. To test for the existence of bubbles, they multiply the term

$$
c\left(\frac{\alpha-1}{\alpha}\right)^{t}
$$

with a dummy variable which equals 1 for the period of a possible bubble, and 0 otherwise. They argue that the null hypothesis that there were no bubbles in these periods cannot be rejected at statistically significant levels. But the question of the last few months of the hyperinflation which plagued Cagan also plagues the empirical analysis of Flood and Garber.

To show this, recall that with perfect foresight, we solved Cagan's model for a particular sequence of the money stock, i.e., $\left\{m_{t}\right\}_{t=0}^{\infty}$. Equivalently, we solved it for a given government policy regime in which the money supply was increasing rapidly. Now suppose that agents expect the government to change the money supply process at some future data $T$. For simplicity, suppose that the current regime has money growing at the zero rate, and that agents expect a change to a higher growth rate $\mu$. More precisely, define

$$
m^{1} \equiv\left\{m_{t}^{1}\right\}_{t=0}^{\infty} \text { such that } m_{t+i}^{1}=m_{t}^{1} \text { for } i \geq 1 .
$$


Then the price level will follow

$$
\begin{aligned}
p_{t} & =\delta \sum_{i=0}^{\infty} \lambda^{i} m_{t}^{1}+c\left(\frac{1}{\lambda}\right)^{t} \\
& =m_{t}^{1}+c\left(\frac{1}{\lambda}\right)^{t}
\end{aligned}
$$

where we have used the fact that $\delta=\frac{1}{1-\alpha}$ and $\sum_{i=0}^{\infty} \lambda^{i}=1-\alpha$.

Now suppose that time $T>t$, agents expect the money supply process to change to

$$
m^{2}=\left\{m_{t+k}\right\}_{t=0}^{\infty} \text { such that } m_{t+k+i}^{2}=m_{t}^{1}+(i+1) \mu \text { for } i \geq 0,
$$

where $k=T-t$ and $\mu>0$.

Notice that

$$
\begin{aligned}
m_{t+k}^{2} & =m_{t}^{1}+\mu \\
m_{t+k+1}^{2} & =m_{t}^{1}+2 \mu=m_{t+k+1}^{2}+\mu
\end{aligned}
$$

and so on. Then agents will calculate the price level to follow

$$
\begin{aligned}
p_{t} & =\delta \sum_{i=0}^{k-1} \lambda^{i} m_{t+i}^{1}+\delta \sum_{i=k}^{\infty} \lambda^{i} m_{t+i}^{2}+c\left(\frac{1}{\lambda}\right)^{t} \text { for } k=T-t \\
& =\delta \sum_{i=0}^{k-1} \lambda^{i} m_{t+i}^{1}+\delta \sum_{i=k}^{\infty} \lambda^{i}\left(m_{t+i}^{1}+(i-k+1) \mu\right)+c\left(\frac{1}{\lambda}\right)^{t} \\
& =\delta \sum_{i=0}^{\infty} \lambda^{i} m_{t+i}^{1}+\delta \sum_{j=0}^{\infty} \mu \lambda^{k+j}(j+1)+c\left(\frac{1}{\lambda}\right)^{t} \text { where } j=i-k \\
& =\delta \sum_{i=0}^{\infty}\left(\frac{\alpha}{1-\alpha}\right)^{i} m_{t}^{1}+\frac{\lambda^{t+k}}{\lambda^{t}} \delta \mu \sum_{j=0}^{\infty}\left(\frac{-\alpha}{1-\alpha}\right)^{j}(j+1)+c\left(\frac{1}{\lambda}\right)^{t} \\
& =m_{t}^{1}+\left[c+\mu \lambda^{t+k} \frac{(1-\alpha)^{2}}{1-\alpha}\right]\left(\frac{1}{\lambda}\right)^{t} \\
& =m_{t}^{1}+\left[c+\mu \lambda^{t+k}(1-\alpha)\right]\left(\frac{1}{\lambda}\right)^{t}
\end{aligned}
$$


for $t=0,1, \ldots$ and $k=T-t$.

So if the researcher estimates the money growth process from observations on money supply from periods before $T$, then he will estimate $m_{t+i}=m_{t+i}^{1}$ whereas agents will expect that the money supply process to change at date $T$. So from the agents' point of view, the price level will be described by (5.7) whereas from the econometrician's point of view, it will be described by (5.5). By not taking intio account the fact that the money growth rate increased at date $t$, the econometrician will erroneously conclude that there is a bubble even if the true value of the coefficient $c=0$. Consequently, the possibility of regime shifts introduces nontrivial problems in the empirical and theoretical analysis of hyperinflations. Flood and Garber suspect that agents expect a regime change in the later part of their sample and so they throw out the last few observations, just as Cagan does, in order to uniquely identify the parameter $c$.

\section{The Effects of a Currency Reform}

Laura LaHaye (1985) explicitly considers the idea that agents expected a currency reform during the last months of the hyperinflation into the original Cagan model. How does the idea of a currency reform help to account for the last few observations which Cagan could not fit? As before, let $m^{1}=\left\{m_{t}^{1}\right\}$ be the money supply process which agents prior to the reform expect and $m^{2}=\left\{m_{t}^{2}\right\}$ be the post-reform money supply process. Also suppose that the reform date is known with certainty by agents as $T$. Then

$$
\begin{aligned}
p_{t} & =\delta \sum_{i=0}^{\infty} \lambda^{i} m_{t+1}^{1}+\delta \sum_{i=k}^{\infty} \lambda^{i} m_{t+i}^{2} \text { where } k=T-t \\
& =\delta \sum_{i=0}^{\infty} \lambda^{i} m_{t+i}^{1}+\delta \lambda^{k} \sum_{i=0}^{\infty} \lambda^{i}\left(m_{t+i+k}^{2}-m_{t+i+k}^{1}\right) .
\end{aligned}
$$

By definition of a reform, $m_{t+i}^{2} \leq m_{t+i}^{1}, i \geq 0$. The effect of a reform which agents believe will occur at date $T$ is to reduce the price level today. Also, as the reform date approaches $(T-t=k)$, the effect on the price level will also grow. So prices will be lower than predicted if the reform is taken into account and also real balances will be higher than 
predicted if the currency reform is taken into account. This is one way of explaining the last few observations that create problems for Cagan and Flood and Garber.

\section{A Hyperinflationary Equilibrium in the Overlapping Gen- erations Model}

Let us conclude this discussion of hyperinflation with an example of an equilibrium model in which the demand for real balances is determined within the model, and let us ask if there can exist a hyperinflationary equilibrium, i.e., one in which the expectations of future prices affect current prices. We can also ask whether there are "bubbles" in this model. Instead of analyzing the price level, it will be more convenient to analyze its inverse, which is equal to the price of money in real terms. Consequently, the existence of a "bubble" in this framework will be taken as the existence of an equilibrium in which the value of real balances goes to zero.

Consider an overlapping generations model with $H$ individuals per generation. Let

$$
U\left(c_{t}^{h}(t), c_{t}^{h}(t+1)\right)=\log \left(c_{t}^{h}(t)\right)+\log \left(c_{t}^{h}(t+1)\right)
$$

be the preferences of an individual $h$ born at time $t$ and let $\left(w_{t}(t), w_{t}(t+1)\right)$ be his endowment vector. Then

$$
\frac{\partial U / \partial c_{t}^{h}(t)}{\partial U / \partial c_{t}^{h}(t+1)}=\frac{c_{t}^{h}(t+1)}{c_{t}^{h}(t)}
$$

We note that

$$
\frac{\partial U / \partial c_{t}^{h}(t)}{\partial U / \partial c_{t}^{h}(t+1)} \rightarrow\left\{\begin{array}{l}
\infty \text { as } \frac{c_{t}^{h}(t)}{c_{t}^{h}(t+1)} \rightarrow 0 \\
0 \text { as } \frac{c_{t}^{h}(t)}{c_{t}^{h}(t+1)} \rightarrow \infty
\end{array}\right.
$$

Assume that the old at $t$ have $M / H$ units of fiat money and $w_{0}(1) / H$ units of time 1 goods as their endowment. Let $p(t)$ be the price level of a unit of fiat money at time $t$ in units of time 2 consumption and let $m^{h}(t)$ be the money holdings of individual $h$ at time $t$. For $t \geq 1$, the young solve the problem: 


$$
\max _{c_{t}^{h}(t), c_{t}^{h}(t+1), m^{h}(t)} \log \left(c_{t}^{h}(t)\right)+\log \left(c_{t}^{h}(t+1)\right)
$$

s.t. $\quad c_{t}^{h}(t)+p(t) m^{h}(t) \leq w_{t}(t)$

$$
\begin{aligned}
& c_{t}^{h}(t+1) \leq w_{t}(t+1)+p(t+1) m^{h}(t) \\
& c_{t}^{h}(t), c_{t}^{h}(t+1), m^{h}(t) \geq 0 .
\end{aligned}
$$

Then

$$
\begin{aligned}
& \frac{1}{c_{t}^{h}(t)} \leq \lambda^{h}(t) \text { with }=\text { if } c_{t}^{h}(t)>0 \\
& \frac{1}{c_{t}^{h}(t+1)} \leq \lambda^{h}(t+1) \text { with }=\text { if } c_{t}^{h}(t+1)>0 \\
& \lambda^{h}(t) p(t) \leq \lambda^{h}(t+1) p(t+1) \text { with }=\text { if } m_{t}^{h}(t)>0,
\end{aligned}
$$

where $\lambda^{h}(t)$ denotes the Lagrange multiplier on the period $t$ budget constraint for consumer $h$.

Market clearing:

$$
\begin{aligned}
& \sum_{h=1}^{H}\left[c_{t}^{h}(t)+c_{t-1}^{h}(t)\right]=\sum_{h=1}^{H}\left[w_{t}(t)+w_{t-1}(t)\right] \\
& \sum_{h=1}^{H} m^{h}(t)=M
\end{aligned}
$$

and $\quad c_{0}^{h}(1)=w_{0}(1)+p(1) M / H$.

With non-satiation of both goods, we know that $c_{t}^{h}(t)$ and $c_{t}^{h}(t+1)$ will be strictly positive. Also, with all members of a given generation being identical, we know that $m^{h}(1)=m(t)=$ $M / H$.

Finally, if $m^{h}(t)=0$ for some $h$, then there will exist opportunities for arbitrage because the cost of holding money in utility terms will be less than its expected benefit in utility 
terms. Thus, we have that

$$
\begin{aligned}
& \lambda^{h}(t) p(t)=\lambda^{h}(t+1) p(t+1) \\
\Rightarrow \quad & p(t) c_{t}^{h}(t+1)=p(t+1) c_{t}^{h}(t) \text { or } \frac{1}{p(t+1)} c_{t}^{h}(t+1)=\frac{1}{p(t)} c_{t}^{h}(t) \\
\Rightarrow \quad & \frac{1}{p(t+1)}\left(w_{t}(t+1)+p(t+1) \frac{M}{H}\right)=\frac{1}{p(t)}\left(w_{t}(t)+p(t) \frac{M}{H}\right) \\
\Rightarrow \quad & \tilde{p}(t+1) w_{t}(t+1)+2 \frac{M}{H}=\tilde{p}(t) w_{t}(t) \\
\Rightarrow \quad & \tilde{p}(t)=\tilde{p}(t+1) \frac{w_{t}(t+1)}{w_{t}(t)}+\frac{2 M}{w_{t}(t) H} .
\end{aligned}
$$

We can consider the solution under two cases.

If $w_{t}(t+1)=0 \quad \forall t \geq 1$, then

$$
p(t)=\frac{w_{t}(t) H}{2 M}>0, \quad t \geq 1 .
$$

This yields a stationary solution in which the price level is constant at all dates.

If $w_{t}(t)=w_{1}$ and $w_{t}(t+1)=w_{2}, t \geq 1$, and $w_{1}>w_{2}$, then

$$
\begin{aligned}
\tilde{p}(t) & =\frac{w_{2}}{w_{1}} \tilde{p}(t+1)+\frac{2 M}{w_{1} H} \\
\text { or } \quad \tilde{p}(t) & =\frac{w_{2}}{w_{1}}\left[\frac{w_{2}}{w_{1}} \tilde{p}(t+1)+\frac{2 M}{w_{1} H}\right]+\frac{2 M}{w_{1} H} \\
\Rightarrow \quad \tilde{p}(t) & =\sum_{i=0}^{\infty}\left(\frac{w_{2}}{w_{1}}\right)^{i} \frac{2 M}{w_{1} H}+c\left(\frac{w_{1}}{w_{2}}\right)^{t} .
\end{aligned}
$$

Notice that if $c \neq 0$, then there will $\mathrm{b}$ an explosive solution to the difference equation describing the price level. But if $\tilde{p}(t) \rightarrow \infty$, then $p(t)=0$ so the value of money in period $t$ in terms of period $t$ consumption goods goes to zero. Alternatively, we have an equilibrium in which the value of the nominal price level goes to infinity. So we have the possibility of hyperinflation in this model. The hyperinflationary equilibrium arises from the multiplicity of equilibria in the overlapping generations model with fiat money. But can bubbles exist for any asset? 


\section{References}

Blanchard, O. J. and Mark Watson (1983). "Bubbles, Rational Expectations, and Financial Markets," in Crises in the Economic and Financial Structure, (Paul Wachtel, ed.), Lexington, Mass: Lexington Books.

Cagan, P. (1956). "The Monetary Dynamics of Hyperinflation." in Studies in the Quantity Theory of Money, (Milton Friedman, ed.), Chiacago: University of Chicago Press.

Flood, Robert J. and Peter M. Garber (1980). "Market Fundamentals versus Price-level Bubbles: The First Tests," Journal of Political Economy 88: 745-770.

LaHaye, Laura (1985). "Inflation and Currency Reform," Journal of Political Economy 93: $537-560$.

Sargent, Thomas J. (1977). "The Demand for Money during Hyperinflations," International Economic Review 18, 59-82.

Sargent, Thomas J. (1979). Macroeconomic Theory, London: Academic Press.

Sargent, Thomas J. (1982). "The Ends of Four Big Hyperinflations," in Inflation: Causes and Effects (Robert E. Hall, ed.) Chicago: University of Chicago Press.

Sargent, Thomas J. and Neil Wallace (1973). "Rational Expectations and the Dynamics of Hyperinflation," International Economic Review 14, 328-350. 